\title{
RESEARCH ON THE TUNNEL EXCAVATED IN URUMQI GLACIER NO. 1, TIANSHAN GLACIOLOGICAL STATION, CHINA
}

\author{
By HUANG MAOHUAN and WANG ZHONGXIANG
}

(Lanzhou Institute of Glaciology and Geocryology, Academia Sinica, Lanzhou, China)

\begin{abstract}
A tunnel was excavated in Urumqi Glacier No. 1 , at the Tianshan Glaciological Station. Ice temperature, ice displacement, deformation, and basal sliding, etc. were observed at regular intervals. It is shown that the temperature near the glacier bed is close to the melting point and that the largest proportion of the overall glacier motion is within the lowermost ice layers. The glacier ice is in a state of compression. The maximum shear strain increases towards the entrance of the tunnel, corresponding to the change in slope of the ice surface, and also towards the bedrock.
\end{abstract}

\section{INTRODUCTION}

The Tianshan Glaciological Station, Academia Sinica, has done much research work, and received many visitors from home and abroad, since it was re-opened in 1980. Research on the tunnel excavated in Urumqi Glacier No. 1 at the Urumqi River headwaters, Tianshan, has been carried out by glaciologists. The main results of this research are now being published in order to obtain opinion and support. Another part of the work, carried out in co-operation with Dr K.A. Echelmeyer of the Geophysical Institute, University of Alaska, at the end of 1984, is being published separately (Echelmeyer and Wang, 1987).

The tunnel is located at the terminus of the western tributary of Urumqi Glacier No. 1 (Fig. 1). It was excavated to a length of $30 \mathrm{~m}$ in 1980 , and extended to $90 \mathrm{~m}$ in the summer of 1981 ; it was then reduced to about $70 \mathrm{~m}$ by ablation at the end of 1983 . Its cross-section was rectangular with a height of $2-2.2 \mathrm{~m}$ and width of $1.5-1.8 \mathrm{~m}$. The floor of the tunnel was almost parallel to the glacier bed with a slope of $2-8^{\circ}$, and a thin ice layer remained on the floor. The altitude of the entrance was $3820 \mathrm{~m}$ a.s.l. in 1983.

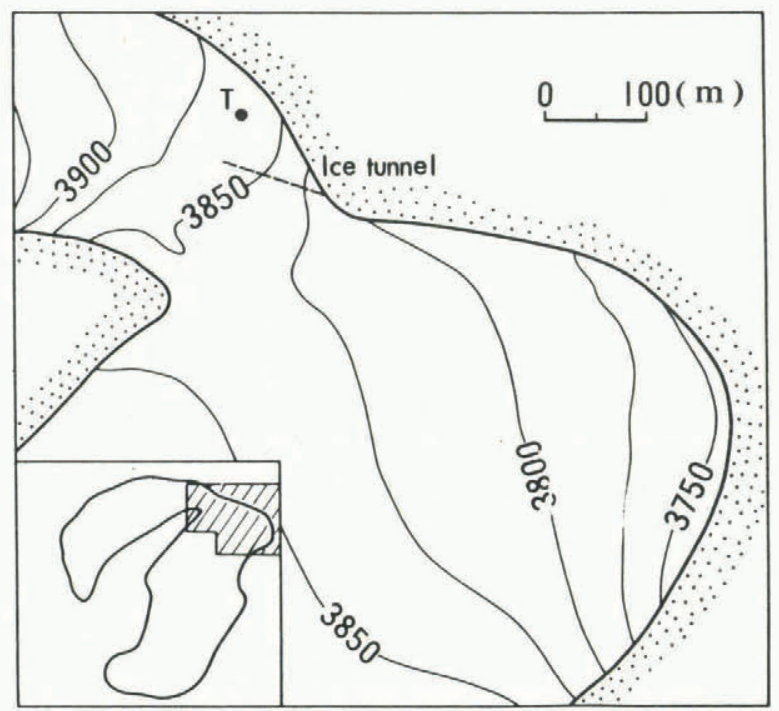

Fig. 1. Map showing the location of the ice tunnel.
Radar measurements have shown that the bed topography adjacent to the tunnel has a relatively even dip close to that at the terminus, without any marked rise or fall (Zhang and others, 1985).

The observations in the tunnel included ice temperature, glacier flow, ice displacement, strain-rate, and basal sliding (Huang and others, 1985; Wang and others, 1985) with the aim of investigating the dynamic mechanism within the basal part of one of the continental-type glaciers in China, which are located in the interior of the continent.

Eight observation sections were established in the tunnel. Their relative positions and distances from the entrance are shown in Figure 2. A lateral shaft, $7.5 \mathrm{~m}$ high, was excavated adjacent to the main tunnel in the southern side of section D. Point $\mathrm{s}$ in Figure 2 is where the surface velocity was measured.

\section{TEMPERATURE}

In their analysis of the temperature regime of Urumqi Glacier No. 1, Ren and others (1985) pointed out that in

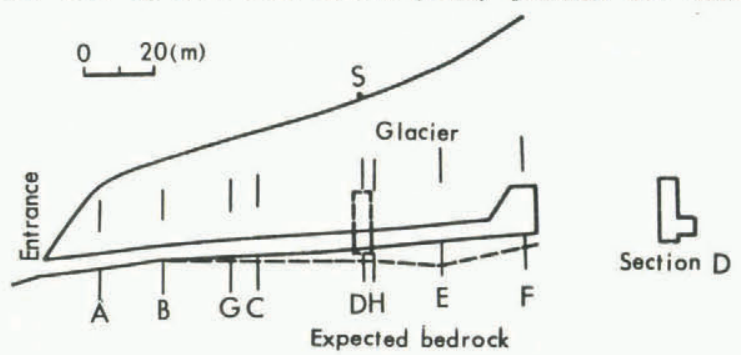

Fig. 2. Longitudinal section of the ice tunnel; the positions of observation sections are also shown.

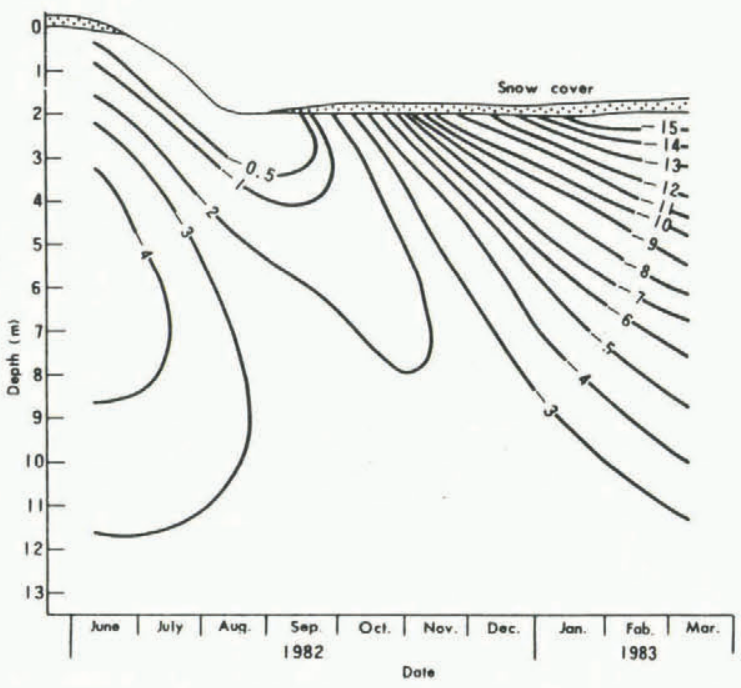

Fig. 3. Temperature diagram at point $\mathrm{T}$ (by courtesy of Ren Jiawen). 
TABLE I. TEMPERATURE OF THE TUNNEL FLOOR $\left({ }^{\circ} \mathrm{C}\right)$ MEASURED FROM AUGUST TO OCTOBER 1982

$\begin{array}{cccccccc}\begin{array}{c}\text { Distance } \\ \text { entrance }\end{array} & \text { Depth } & 20 \text { Aug. } & \text { 31 Aug. } & 10 \text { Sep. } & 19 \text { Sep. } & 1 \text { Oct. } & 15 \text { Oct. } \\ \text { m } & \mathrm{m} & & & & & & \\ 30 & 0.60 & -0.9 & -0.9 & -0.9 & -0.9 & -1.0 & -0.9 \\ 50 & 2.40 & -0.1 & -0.1 & -0.1 & -0.1 & -0.1 & -0.1 \\ 60 & 2.69 & -0.1 & -0.1 & -0.1 & -0.1 & -0.1 & -0.1 \\ 69 & 1.65 & -0.1 & -0.1 & -0.1 & -0.2 & -0.2 & -0.2 \\ 69 & 0 \text { (air) } & -0.1 & -0.1 & -0.1 & -0.1 & -0.1 & -0.1\end{array}$
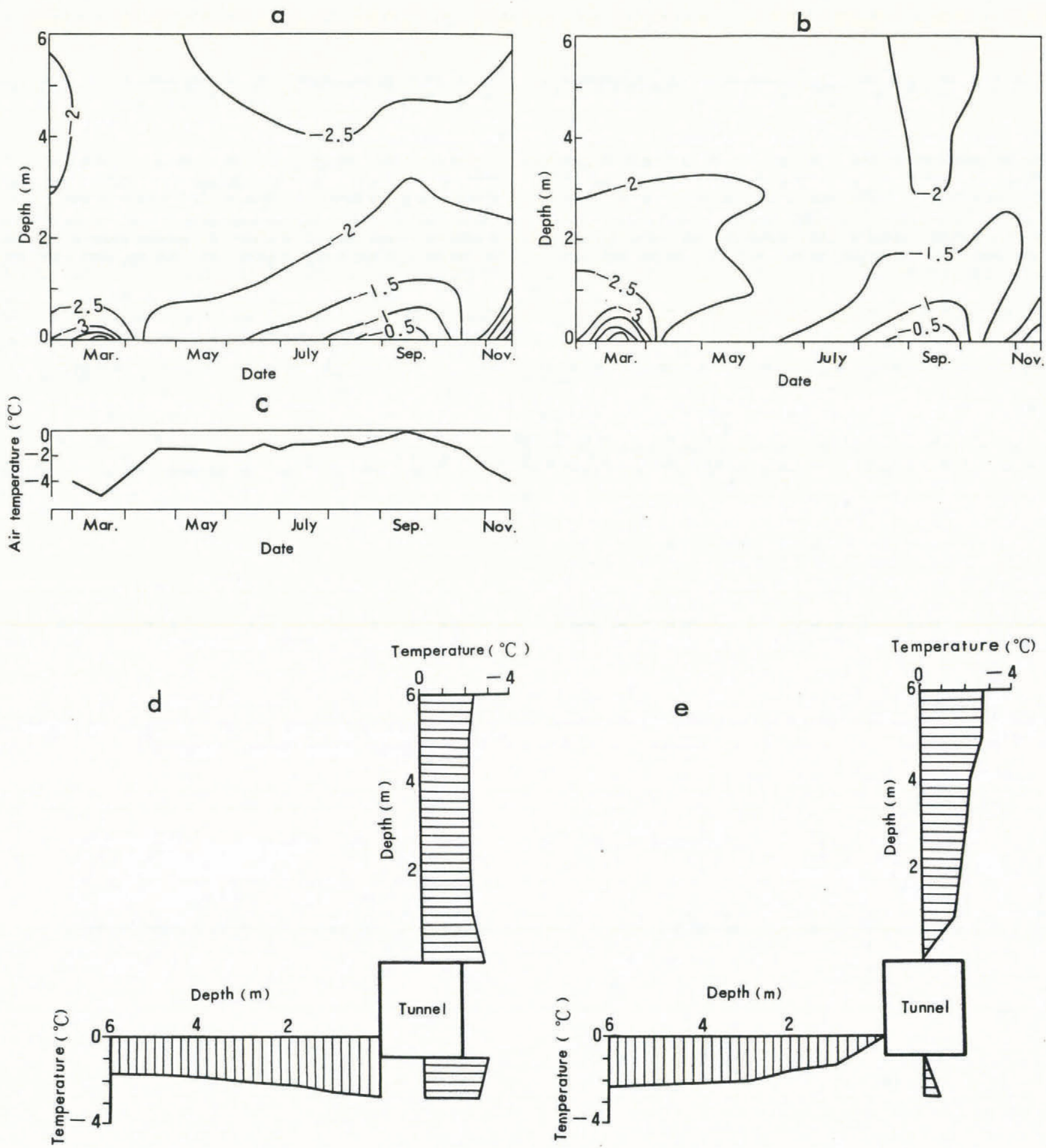

Fig. 4. Temperature diagrams at section G. (a) and (b) Inside the ceiling and lateral wall of the tunnel, respectively. (c) Air temperature in the tunnel. (d) and (e) Temperature profiles around the tumel on 15 March and 13 September 1983, respectively. 
TABLE II. TEMPERATURE OF THE TUNNEL FLOOR $\left({ }^{\circ} \mathrm{C}\right)$ MEASURED FROM FEBRUARY TO NOVEMBER 1983 BY QUARTZ THERMOMETERS

$\begin{array}{lcccc}\text { Section } & G & H & E & F \\ \text { Depth (m) } & 0.9 & 2.3 & 3.0 & 1.8 \\ \text { Maximum temperature }\left({ }^{\circ} \mathrm{C}\right) & -0.41 & -0.53 & -0.24 & -0.30 \\ \text { Minimum temperature }\left({ }^{\circ} \mathrm{C}\right) & -2.85 & -1.22 & -0.62 & -0.32\end{array}$

this glacier the ice temperature rises rapidly with increasing depth; therefore, the estimated temperature at the glacier bed is at melting point in some places, even though the temperature near the surface is quite low. An example is shown in Figure 3. It is a temperature diagram measured from June 1982 to March 1983 at point T (shown in Figure 1) which was slightly higher and not far from the tunnel, where the highest temperature at a depth of $13 \mathrm{~m}$ was $-2.5^{\circ} \mathrm{C}$, while the lowest at the surface was $-15^{\circ} \mathrm{C}$.

The temperature of the tunnel floor, measured from August to October 1982 (Table I), was close to melting point. The temperature of the tunnel floor was measured again at four sections from February to November 1983, using quartz thermometers with an accuracy of $0.01^{\circ} \mathrm{C}$. From the measured depth, the interface between the ice layer and the ice-laden debris layer was reached. The main results are given in Table II. The highest temperature measured was $-0.24^{\circ} \mathrm{C}$ and the lowest $-2.85^{\circ} \mathrm{C}$. Meanwhile, at section $G$ the ceiling, the lateral wall, and the floor of the tunnel were drilled to set thermometers up to a depth of $6 \mathrm{~m}$. The temperatures measured at section $G$ are shown in Figure 4. In Figure $4 a$ and $b$ are the temperature diagrams measured inside the ceiling and the lateral wall of the tunnel, respectively; Figure $4 \mathrm{c}$ is the air-temperature curve in the tunnel; Figure $4 \mathrm{~d}$ and $\mathrm{e}$ are the temperature profiles around the tunnel on the coldest and the warmest days, i.e. 15 March and 13 September 1983, respectively. Figure $4 \mathrm{a}, \mathrm{b}, \mathrm{d}$, and $\mathrm{e}$ are drawn on the assumption that the temperature at the ice surface is equal to the air temperature. From Figure $4 \mathrm{c}$ one can see that, from mid March to mid September, the air temperature increased gradually to a maximum of $0^{\circ} \mathrm{C}$, and we believe that from mid September to mid March the following year it should have been falling gradually to a minimum of about $-5^{\circ} \mathrm{C}$. Comparing the air temperature with that of the ice between the ice surface and a depth of $2 \mathrm{~m}$ around the tunnel, we can see that the ice was warmed by the air from mid April to mid October, and then the air was warmed by the ice from mid October to mid April the following year; both periods were almost 6 months. It is certain that heat transfer was going to stabilize because the tunnel had been excavated 3 years previously. According to the estimate of Ren Jiawen, based on data from 1959 to 1982 , the mean annual air temperature at the tunnel entrance $(3820 \mathrm{~m}$ a.s.l.) was $-8.3^{\circ} \mathrm{C}$, which is much lower than the surrounding ice temperature at section $\mathrm{G}\left(-2^{\circ} \mathrm{C}\right.$ estimated $)$. It is clear that heat was being transferred from the tunnel ice to the atmosphere each year. Moreover, sublimation is of ten seen inside the tunnel, which implies that heat is being lost from the tunnel wall. In addition, we saw water springing up from a hole in the floor of the tunnel in September 1983. All of the above-mentioned points indicate that the ice temperature might have been even higher and nearer to melting point if the tunnel had not been excavated.

\section{MEASUREMENT OF DISPLACEMENT}

In the $7.5 \mathrm{~m}$ high shaft excavated at section $\mathrm{D}$, a vertical line of 14 pegs was fixed on the southern wall for observing horizontal displacement and calculating flow rate due to deformation of the glacier. The distance between two adjacent pegs was equal and $50 \mathrm{~cm}$. The pegs were fixed and observed initially on 13 January, and then observed three times on 17 April, 9 September, and 28 November 1983. During each observation a plumb line was hung from the uppermost peg to form a vertical line; horizontal distances between each peg and the vertical line were then measured by a steel ruler. Thus, the different displacements between any two adjacent pegs, $\Delta l$, was determined and then smoothed to reduce the observational errors. Observation showed that there was an angle of about $20^{\circ}$ between the observed wall and the flow direction of the glacier. Therefore, in the flow direction, the different displacements between any two adjacent pegs would be $\Delta l^{\prime}=\Delta l / \cos 20^{\circ}$. Approximately, we suppose

$$
\mathrm{d} u / \mathrm{d}(H-y)=\Delta l^{\prime} / \Delta T \Delta Y
$$

where $u$ is the horizontal component of the flow velocity; $H$ is the ice thickness from the surface to the lowest peg (it varies with time because of ablation at the surface); $y$ is the vertical coordinate with the origin at the lowest peg and in a positive direction upwards; $\Delta T$ is the flow duration from the initial observation date to a later observation date; and $\Delta Y$ is the vertical distance between any two adjacent pegs. Suppose there is a power relationship between $\mathrm{d} u / \mathrm{d}(H-y)$ and $(H-y)$, namely

$$
\mathrm{d} u / \mathrm{d}(H-y)=a(H-y)^{b}
$$

where $a$ and $b$ are constants that can be determined by regression analysis. We can then extrapolate Equation (2) to $y=H$ and integrate it from $y=0$ to $y=H$ to estimate roughly the flow rate due to deformation, $u_{\mathrm{d}}^{\prime}$, from the surface to the lowest peg, namely

$$
u_{\mathrm{d}}^{\prime}=a H^{b+1}(b+1) \text {. }
$$

Table III summarizes the values determined. The value of $u_{\mathrm{d}}^{\prime}(57-82 \mathrm{~cm} /$ year $)$ is not too large and a small decrease in the cold season seems reasonable.

TABLE III. CALCULATED RESULTS OF DISPLACEMENT AT SECTION D

$\begin{array}{lccccc}\text { Duration } & \begin{array}{c}a \\ \mathrm{~cm}^{-6} \mathrm{a}^{-1}\end{array} & b & R^{*} & \begin{array}{c}H \\ \mathrm{~cm}\end{array} & \begin{array}{r}u_{\mathrm{d}}^{\prime} \\ \mathrm{cm} \mathrm{a}^{-1}\end{array} \\ \text { 13 Jan.-17 Apr. } 5.4 \times 10^{-14} & 3.68 & 0.799 & 2255 & 57 \\ \text { 13 Jan.-9 Sep. 2.1 } \times 10^{-10} & 2.63 & 0.754 & 2185 & 78 \\ \text { 13 Jan.-28 Nov. } 9.2 \times 10^{-8} & 1.81 & 0.799 & 2181 & 82\end{array}$

${ }^{*}$ Retrogression coefficient.

According to a previous study on flow in Urumqi Glacier No. 1 (Sun and others, 1985), the horizontal velocity at section B (near the upper part of the tunnel) was $3.18-7.02 \mathrm{~m} / \mathrm{year}$, and at section $\mathbf{A}$ (near the lower part of the tunnel) it was $2.48 \mathrm{~m}$ /year in the year of 1981-82. We have observed the horizontal surface velocity over a period of $235 \mathrm{~d}$ at point $\mathrm{s}$ on section $\mathrm{D}$ (Fig. 2) as being $4.87 \mathrm{~m} /$ year. Suppose the velocity at the surface in section $D$ is $u_{\mathrm{s}}=4.87 \mathrm{~m} /$ year and

$$
u_{\mathrm{s}}=u_{\mathrm{d}}^{\prime}+u_{\mathrm{b}}^{\prime},
$$

then $u_{\mathrm{b}}^{\prime}=4.05-4.30 \mathrm{~m} /$ year, i.e. $83-88 \%$ of the overall glacier motion, is found where $u_{\mathrm{b}}^{\prime}$ is the rate of motion below the lowest peg. Below the lowest peg, there is a $3.4 \mathrm{~m}$ ice layer down to the recently discovered basal drift. This ice layer consists of clean ice within which are intercalated some ice-laden debris layers, and there are some small cavities beneath. According to observations in 1984 (Echelmeyer and Wang, 1987), three mechanisms of glacier flow have been observed below the lowest peg. They are: (1) enhanced deformation of the frozen and ice-laden drift; (2) motion across discrete shear planes or shear bands within the frozen drift or at the ice-drift interface; and (3) basal sliding at the ice-rock interface. In combination, they contribute much to $u_{\mathrm{b}}^{\prime}$. In addition, across a shear plane inside the tunnel, we observed a relative movement of $2.1 \mathrm{~m} /$ year from 7 December to 28 June 1981 . 
TABLE IV. LOCATION OF CIRCULAR PEG ARRAYS

\begin{tabular}{|c|c|c|c|c|c|c|c|c|c|c|c|c|c|c|c|c|}
\hline Section & Entrance & & $A$ & $B$ & & C & 5 & & & $D$ & & & & 1 & $E$ & $F$ \\
\hline Array & - & $A-1$ & $A-2$ & $\mathrm{~B}-1$ & $\mathrm{~B}-2$ & $C-1$ & $C-2$ & $D-1$ & $\mathrm{D}-2$ & $D-3$ & $D-4$ & $D-5$ & $D-6$ & $E-1$ & $E-2$ & $F-1$ \\
\hline Array height* $(\mathrm{cm})$ & - & 100 & 60 & 127 & 77 & 95 & 45 & 600 & 500 & 400 & 300 & 200 & 100 & 95 & 45 & 95 \\
\hline Distance between & 1 & & & & & & & & & & & & 1 & & & 10 \\
\hline
\end{tabular}

sections $(\mathrm{m})$

*Array height measured from array's centre to tunnel floor.

\section{DEFORMATION}

In 1983, two circular peg arrays for observing ice strain were fixed on the southern wall of the tunnel at sections A, B, C, E, and F, respectively (denoted by A-1, $\mathrm{A}-2, \mathrm{~B}-1, \mathrm{~B}-2, \mathrm{C}-1, \mathrm{C}-2, \mathrm{E}-1, \mathrm{E}-2, \mathrm{~F}-1$, and $\mathrm{F}-2$ ), and six arrays on the southern wall of the shaft at section $D$ (denoted by $\mathrm{D}-1, \mathrm{D}-2, \ldots \mathrm{D}-6)$. Table IV summarizes the locations of these arrays for observing ice strain. Each circular peg array comprised nine pegs frozen into the ice as shown in Figure 5. These arrays were fixed and observed initially on 13 January and then re-observed three times on 19 April, 9 September, and 28 November, 1983. The observational data are published in the Annual report on the

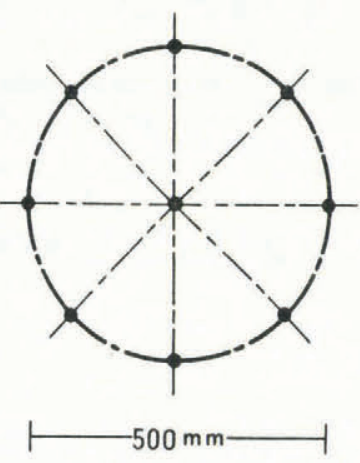

Fig. 5. Circular peg array for observing ice deformation.

work at Tianshan Glaciological Station, No. 2. Polar coordinates were assumed for observation and the centre of the circular array was assumed as the origin. The polar radius of each point in the array was measured with a steel ruler, and the angular orientation between each radius and the horizontal line by a protractor, by which $1 \mathrm{~mm}$ and $0.5^{\circ}$ could be read, respectively.

Initially, we assumed that all observed deformation occurred in the principal plane, i.e. the ice wall where deformation was observed was a principal plane for glacier deformation. Therefore, the observed data can be processed as a problem of plane deformation. Actually, the directions of the tunnel and the flow line were not parallel to each other, with an angle of $20^{\circ}$ between them. Therefore, there was a certain error in the results.

Secondly, we assumed that deformation was homogeneous within the range of the observed array. So formulae for homogeneous deformation could be applied to calculations. However, since the deformation of glacier ice is not perfectly homogeneous, this also caused some error. But a recent investigation shows that the homogeneous deformation assumption is not the cause of any obvious error (Huang and Wang, 1986).

A Lagrangian form was applied to describe the plane homogeneous deformation. Suppose a point on a deforming body $\mathrm{B}(x, y)$ deformed to $\mathrm{B}^{\prime}\left(x^{\prime}, y^{\prime}\right)$. Provided the centre of the circular array is fixed, rigid translation motion might be eliminated. Taking coordinates $x, y$ before deformation as independent variables, point-set transformation equations after deformation will be

$$
\begin{aligned}
& x^{\prime}=a x+b y, \\
& y^{\prime}=c x+d y .
\end{aligned}
$$

Let the values observed on 13 January be the coordinates before deformation, and the values observed later as the coordinates after deformation. The values of $a, b, c$, and $d$ can be determined by substituting values of two adjacent points in a circular array, which was observed before and after deformation, into Equations (5). Then eight arrays of $a, b, c$, and $d$ are obtained. Similarly, by substituting values of two points with a $90^{\circ}$ difference in circumference angle, another eight arrays of $a, b, c$, and $d$ are also obtained. Arithmetic mean values of $a, b, c$ and $d$ can be determined from these 16 arrays. Actually, only 12 intermediate arrays were used, eliminating the extreme values. Then, the major and minor axes of the deformation ellipses and their directions, the rotations of principal axes, maximum shear strains, and area-compression rate can be calculated by a currently used method (Han, 1984). From the results calculated up to 19 April, 9 September, and 28 November, there is no regularity in temporal variation. We then transform these calculated results into equivalence values of 1 year and take their averages. The final results are summarized in Table V. Deformation ellipses, equivalent to 1 year, for each circular array, are shown in Figure 6 .

From Table $\mathrm{V}$ and Figure 6 , the following is a summary:

1. One principal direction is shortened and one is elongated for every circular array in the wall. But the shortening ratio is larger than the elongation ratio. It therefore appears that there is generally a state of compression, which implies extension in the third direction which causes closure of the tunnel. However, the closure rate is not very fast, so the tunnel can last for many years.

2. There are certain regularities in that the elongation ratio of the major axis, the compression ratio of the minor axis, the rotation of the principal axis, and the maximum shear strain for each circular array increase gradually from the back wall towards the tunnel entrance. The areacompression rate also increases but not too obviously.

3. The maximum shear strain-rate for each section increases towards the bed in most cases.

\section{STRESS}

When the components of strain-rate at a point in an ice body are known, the components of stress at the same point can be determined by solving certain basic equations (Paterson, 1981, chapters 3 and 6). The lengths of the axes of the deformation ellipse minus 1 may be taken as strain $\epsilon^{\mathrm{C}}$ in the principal direction, which is well known as conventional strain. If a large strain had occurred, we would rather apply natural strain $\epsilon^{\mathrm{N}}$, which is more fitted to expressing finite strain rather than conventional strain. The relationship between $\epsilon^{\mathrm{C}}$ and $\epsilon^{\mathrm{N}}$ is

$$
\epsilon^{N}=\ln \left(1+\epsilon^{C}\right) \text {. }
$$

Furthermore, the value for strain, equivalent to 1 year, may be taken as the strain-rate $\dot{\epsilon}$ with a unit of year ${ }^{-1}$. 
TABLE V. CALCULATED RESUlTS, EQUiVALENT TO 1 YEAR, OF DEFORMATION AT EACH CIRCULAR PEG ARRAY

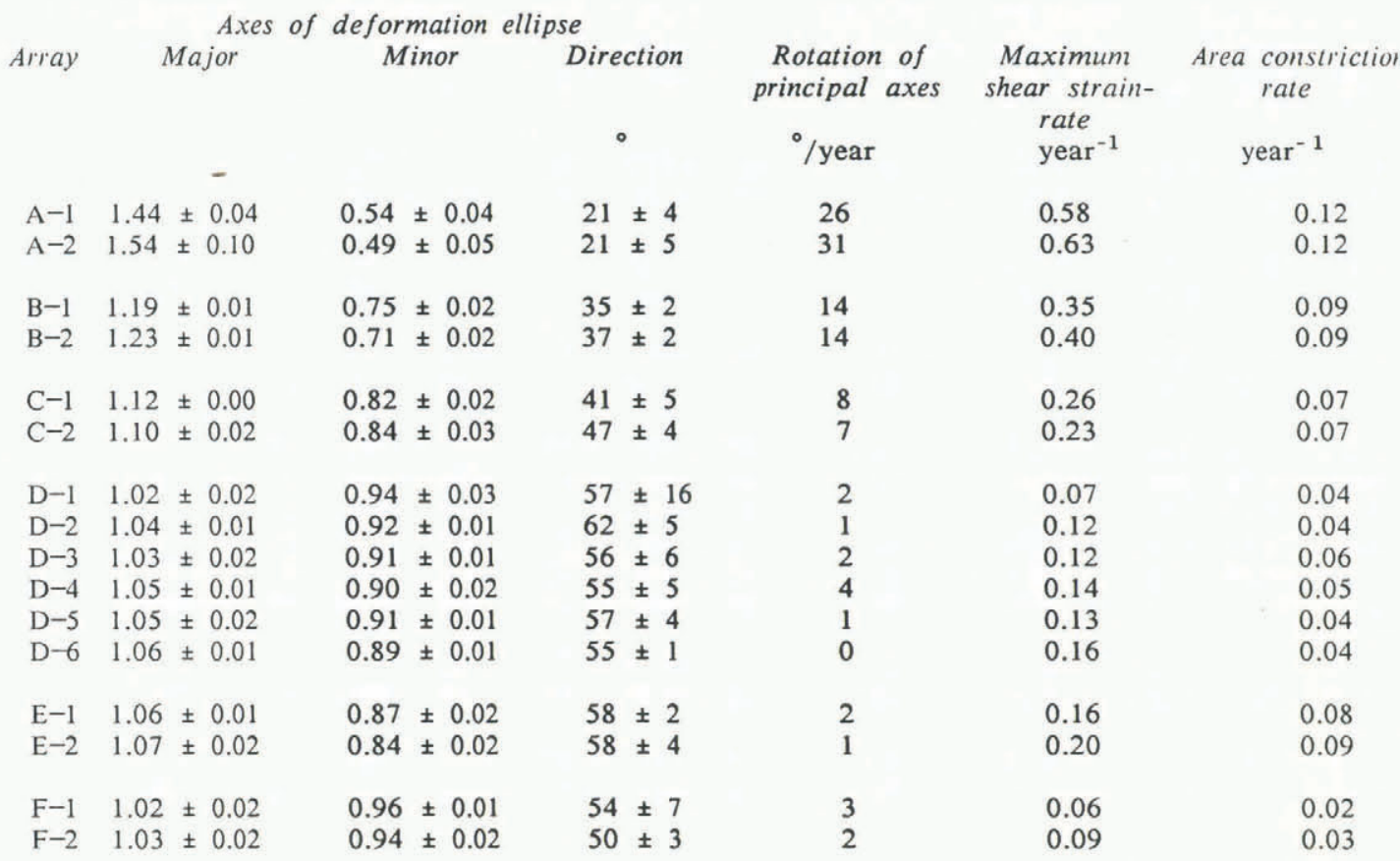
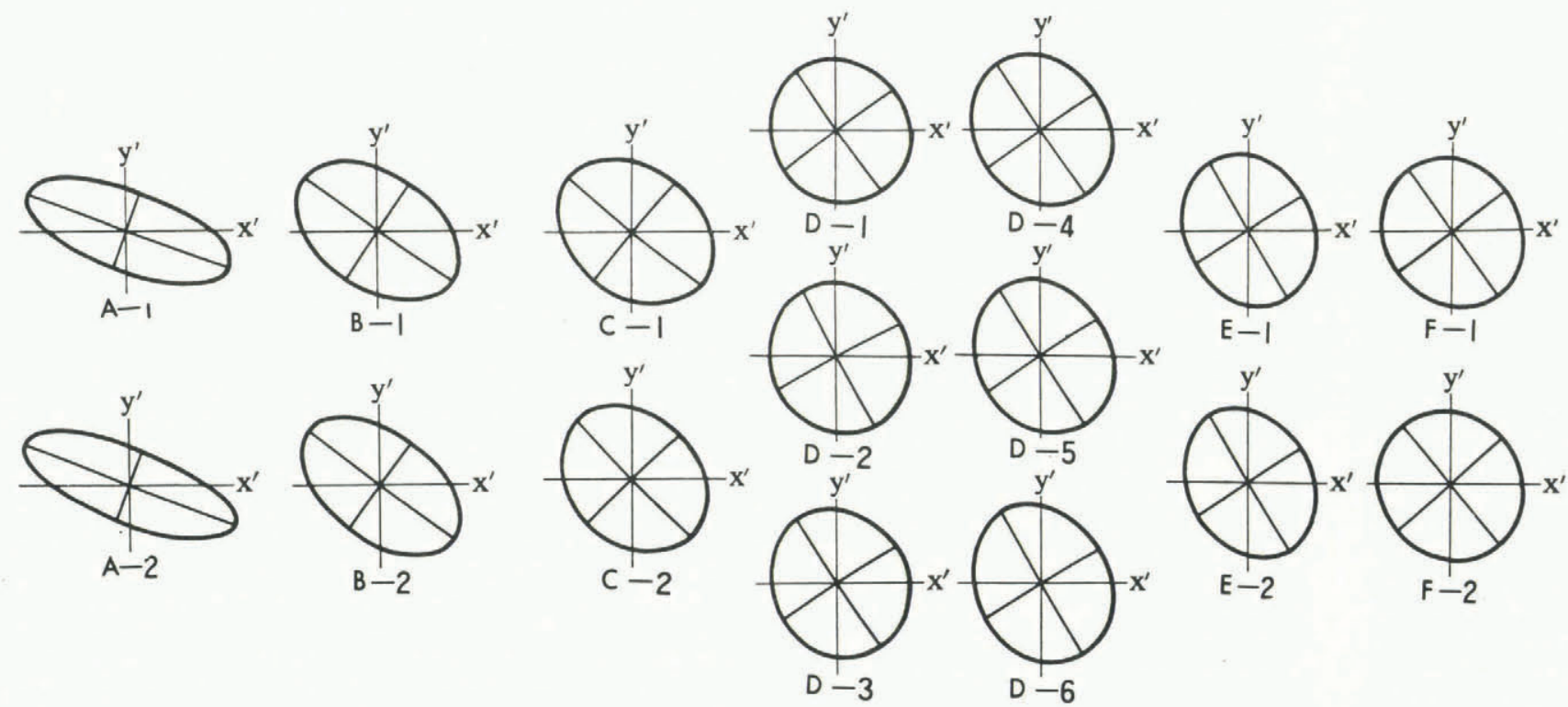

Fig. 6. Deformation ellipses equivalent to 1 year. $x^{\prime}$-axis positive from tunnel entrance invard.

The two flow-law parameter values of $n=3$ and $A=$ $5 \times 10^{-15}\left(\mathrm{~s}^{-1} \mathrm{kPa}^{-3}\right)$ are used for calculations because the ice temperature inside the tunnel is close to $0^{\circ} \mathrm{C}$.

The calculated results are summarized in Table VI. In this table, the subscripts 1,2 , and 3 denote the means of the first, second, and third principal directions, where the third principal direction is perpendicular to the tunnel wall. Assuming that ice is an incompressible material, $\dot{\epsilon}_{3}^{N}$ can be derived from $\dot{\epsilon}_{1}^{\mathrm{N}}$ and $\dot{\epsilon}_{2}^{\mathrm{N}}$. At the tunnel wall itself, there is only the action of atmospheric pressure because it is a free ice surface. So we take $60 \mathrm{kPa}$, the equivalent to the mean atmospheric pressure at the altitude of the tunnel, as the principal stress at the tunnel wall. Then the hydrostatic pressure can be determined.
The stress states in the ice around the tunnel can be summarized as follows:

1. The effective shear stress and stress deviators increase from the back wall of the tunnel towards the entrance, corresponding to the increase in the slope of the ice surface, and they also generally increase towards the bedrock. But the stress deviators $\sigma_{3}^{\prime}$ remain at a low value without any obvious fluctuation.

2. The maximum (compressive) principal stress increases while $\sigma_{1}$ decreases from the back wall of the tunnel towards the entrance.

3. Therefore, the maximum shear clearly increases from the back wall of the tunnel towards the entrance but it acts 
TABLE VI. CALCULATED COMPONENTS OF STRAIN-RATE $\left(\mathrm{year}^{-1}\right.$ ) AND STRESS (kPa)

\begin{tabular}{|c|c|c|c|c|c|c|c|c|c|c|c|c|}
\hline \multirow[t]{2}{*}{ Array } & \multicolumn{3}{|c|}{$\begin{array}{c}\text { Natural } \\
\text { strain-rate }\end{array}$} & \multirow{2}{*}{$\begin{array}{c}\text { Effective } \\
\text { shear-rate } \\
\dot{\epsilon}\end{array}$} & \multirow{2}{*}{$\begin{array}{c}\text { Effective } \\
\text { shear stress } \\
\tau\end{array}$} & \multicolumn{3}{|c|}{$\begin{array}{c}\text { Stress } \\
\text { deviators }\end{array}$} & \multicolumn{3}{|c|}{$\begin{array}{l}\text { Principal } \\
\text { stress }\end{array}$} & \multirow{2}{*}{$\begin{array}{c}\text { Hydrostatic } \\
\text { pressure } \\
\sigma\end{array}$} \\
\hline & $\dot{\epsilon}_{1}^{N}$ & $\dot{\epsilon}_{2}^{\mathrm{N}}$ & $\dot{\epsilon}_{3}^{N}$ & & & $\sigma_{1}^{\prime}$ & $a_{2}^{\prime}$ & $\sigma_{3}^{\prime}$ & $\sigma_{1}$ & $\sigma_{2}$ & $\sigma_{3}$ & \\
\hline $\begin{array}{l}A-1 \\
A-2\end{array}$ & $\begin{array}{l}0.36 \\
0.43\end{array}$ & $\begin{array}{l}-0.62 \\
-0.72\end{array}$ & $\begin{array}{l}0.26 \\
0.29\end{array}$ & $\begin{array}{l}0.54 \\
0.63\end{array}$ & $\begin{array}{l}151 \\
158\end{array}$ & $\begin{array}{l}101 \\
109\end{array}$ & $\begin{array}{l}-173 \\
-182\end{array}$ & $\begin{array}{l}72 \\
73\end{array}$ & $\begin{array}{l}-31 \\
-24\end{array}$ & $\begin{array}{l}-305 \\
-314\end{array}$ & $\begin{array}{l}-60 \\
-60\end{array}$ & $\begin{array}{l}-132 \\
-133\end{array}$ \\
\hline $\begin{array}{l}B-1 \\
B-2\end{array}$ & $\begin{array}{l}0.17 \\
0.21\end{array}$ & $\begin{array}{l}-0.29 \\
-0.34\end{array}$ & $\begin{array}{l}0.12 \\
0.13\end{array}$ & $\begin{array}{l}0.26 \\
0.30\end{array}$ & $\begin{array}{l}117 \\
124\end{array}$ & $\begin{array}{l}80 \\
86\end{array}$ & $\begin{array}{l}-135 \\
-142\end{array}$ & $\begin{array}{l}55 \\
56\end{array}$ & $\begin{array}{l}-36 \\
-30\end{array}$ & $\begin{array}{l}-250 \\
-258\end{array}$ & $\begin{array}{l}-60 \\
-60\end{array}$ & $\begin{array}{l}-115 \\
-116\end{array}$ \\
\hline $\begin{array}{l}\mathrm{C}-1 \\
\mathrm{C}-2\end{array}$ & $\begin{array}{l}0.12 \\
0.10\end{array}$ & $\begin{array}{l}-0.20 \\
-0.18\end{array}$ & $\begin{array}{l}0.09 \\
0.08\end{array}$ & $\begin{array}{l}0.17 \\
0.15\end{array}$ & $\begin{array}{r}103 \\
99\end{array}$ & $\begin{array}{l}68 \\
63\end{array}$ & $\begin{array}{l}-119 \\
-114\end{array}$ & $\begin{array}{l}51 \\
51\end{array}$ & $\begin{array}{l}-43 \\
-49\end{array}$ & $\begin{array}{l}-230 \\
-226\end{array}$ & $\begin{array}{l}-60 \\
-60\end{array}$ & $\begin{array}{l}-111 \\
-111\end{array}$ \\
\hline $\begin{array}{l}D-1 \\
D-2 \\
D-3 \\
D-4 \\
D-5 \\
D-6\end{array}$ & $\begin{array}{l}0.02 \\
0.04 \\
0.03 \\
0.05 \\
0.05 \\
0.06\end{array}$ & $\begin{array}{l}-0.06 \\
-0.08 \\
-0.10 \\
-0.10 \\
-0.09 \\
-0.11\end{array}$ & $\begin{array}{l}0.04 \\
0.04 \\
0.06 \\
0.06 \\
0.04 \\
0.05\end{array}$ & $\begin{array}{l}0.05 \\
0.07 \\
0.09 \\
0.09 \\
0.08 \\
0.10\end{array}$ & $\begin{array}{l}69 \\
77 \\
81 \\
83 \\
80 \\
85\end{array}$ & $\begin{array}{l}26 \\
46 \\
31 \\
44 \\
51 \\
54\end{array}$ & $\begin{array}{l}-79 \\
-89 \\
-92 \\
-95 \\
-93 \\
-98\end{array}$ & $\begin{array}{l}53 \\
44 \\
61 \\
51 \\
42 \\
44\end{array}$ & $\begin{array}{l}-87 \\
-58 \\
-90 \\
-67 \\
-51 \\
-49\end{array}$ & $\begin{array}{l}-191 \\
-193 \\
-214 \\
-207 \\
-195 \\
-202\end{array}$ & $\begin{array}{l}-60 \\
-60 \\
-60 \\
-60 \\
-60 \\
-60\end{array}$ & $\begin{array}{l}-113 \\
-104 \\
-121 \\
-111 \\
-102 \\
-104\end{array}$ \\
\hline $\begin{array}{l}E-1 \\
E-2\end{array}$ & $\begin{array}{l}0.05 \\
0.07\end{array}$ & $\begin{array}{l}-0.14 \\
-0.17\end{array}$ & $\begin{array}{l}0.08 \\
0.10\end{array}$ & $\begin{array}{l}0.12 \\
0.15\end{array}$ & $\begin{array}{l}91 \\
98\end{array}$ & $\begin{array}{l}41 \\
46\end{array}$ & $\begin{array}{l}-104 \\
-113\end{array}$ & $\begin{array}{l}63 \\
66\end{array}$ & $\begin{array}{l}-82 \\
-80\end{array}$ & $\begin{array}{l}-227 \\
-239\end{array}$ & $\begin{array}{l}-60 \\
-60\end{array}$ & $\begin{array}{l}-123 \\
-126\end{array}$ \\
\hline $\begin{array}{l}F-1 \\
F-2\end{array}$ & $\begin{array}{l}0.02 \\
0.03\end{array}$ & $\begin{array}{l}-0.04 \\
-0.06\end{array}$ & $\begin{array}{l}0.02 \\
0.03\end{array}$ & $\begin{array}{l}0.04 \\
0.05\end{array}$ & $\begin{array}{l}62 \\
70\end{array}$ & $\begin{array}{l}39 \\
38\end{array}$ & $\begin{array}{l}-71 \\
-81\end{array}$ & $\begin{array}{l}32 \\
43\end{array}$ & $\begin{array}{l}-52 \\
-65\end{array}$ & $\begin{array}{l}-163 \\
-184\end{array}$ & $\begin{array}{l}-60 \\
-60\end{array}$ & $\begin{array}{r}-92 \\
-103\end{array}$ \\
\hline
\end{tabular}

in a plane parallel to the wall at sections A, B, and C, and in a plane perpendicular to the wall at sections $\mathrm{D}, \mathrm{E}$, and $\mathrm{F}$ where $\left|\sigma_{3}\right|<\left|\sigma_{1}\right|$. Nowhere is the lateral extension of the wall very strong and closure of the tunnel progresses only slowly.

4. The hydrostatic pressure is at a low level and probably increases from the back wall of the tunnel towards the entrance.

\section{SUMMARY}

In order to investigate the dynamic mechanism within the basal part of a glacier, observation of its motion near the bedrock in an excavated tunnel in the ice has produced many important results, even though excavation of a tunnel disrupts the natural stress and temperature fields, causing a certain amount of distortion. Observations have shown that the temperature of the ice near the bedrock is close to melting point. The greater part of the overall motion at the investigation site occurs only within the lowermost part of the glacier. The maximum shear strain acts mainly in a principal plane parallel to the flow line and gradually increases from the back wall of the tunnel towards the entrance, corresponding to the change in slope of ice surface, and also towards the bedrock. The closure rate of the tunnel is relatively slow.

\section{REFERENCES}

Echelmeyer, K., and Wang Zhongxiang. 1987. Direct observation of basal sliding and deformation of basal drift at sub-freezing temperatures. Journal of Glaciology, Vol. 33, No. 113 , p. 83-98.
Han Yuying. 1984. Geometry of finite deformation and its application to geology. Peking, Ti-chih Ch'u-pan-she. [In Chinese.]

Huang Maohuan, and Wang Zhongxiang. 1986. Study of inhomogeneous deformation in a glacier. Journal of Glaciology and Geocryology, Vol. 8, No. 4. [In Chinese.]

Huang Maohuan, and others. 1985. Study of the strain and stress in the bottom layer of Glacier No. 1 in the Urumqi river headwaters, by Huang Maohuan, Wang Zhongxiang, and Song Genhai. Journal of Glaciology and Geocryology, Vol. 7, No. 4, p. 305-15. [In Chinese.]

Paterson, W.S.B. 1981. The physics of glaciers. Second edition. Oxford, etc., Pergamon Press.

Ren Jiawen, and others. 1985. A study of ice temperature in No. 1 Glacier in the Urumqi river headwaters, Tianshan, by Ren Jiawen, Zhang Jinhua, and Huang Maohuan. Journal of Glaciology and Geocryology, Vol. 7, No. 2, p. 141-52. [In Chinese.]

Sun Zuozhe, and others. 1985. Flow characteristics of Glacier No. 1 at the headwaters of Urumqi river, Tianshan, by Sun Zuozhe, Chen Yaowu, You Genxiang, and Han Jiankang. Journal of Glaciology and Geocryology, Vol. 7, No. 1, p. 27-40. [In Chinese.]

Wang Zhongxiang, and others. 1985. Observation and experiment on inner flow characteristics of Glacier No. 1 in the Urumqi river headwaters, Tianshan, by Wang Zhongxiang, Song Genhai, and $\mathrm{Li}$ Gang. Journal of Glaciology and Geocryology, Vol. 7, No. 2, p. 123-32. [In Chinese.]

Zhang Xiangsong, and others. 1985. Radar measuring ice thickness of No. 1 Glacier at the source of Urumqi river, Tianshan, by Zhang Xiangsong, Zhu Guocai, Qian Songlin, Chen Jiyang, and Shen Ying. Journal of Glaciology and Geocryology, Vol. 7, No. 2, p. 153-62. [In Chinese.] 